\title{
The Narrative Form of Music Text and Its Sound Vocabulary
}

\author{
Xiuming $\mathbf{L i}^{1,2}$ \\ ${ }^{1}$ School of Music, Shaanxi Normal University, Xi'an, China \\ ${ }^{2}$ Teacher Education College, Sichuan University of Arts and Science, Dazhou, China \\ Email: 58958364@qq.com
}

How to cite this paper: Li, X. M. (2021). The Narrative Form of Music Text and Its Sound Vocabulary. Open Journal of Social Sciences, 9, 102-109.

https://doi.org/10.4236/jss.2021.92007

Received: January 4, 2021

Accepted: February 7, 2021

Published: February 10, 2021

Copyright (c) 2021 by author(s) and Scientific Research Publishing Inc. This work is licensed under the Creative Commons Attribution International License (CC BY 4.0).

http://creativecommons.org/licenses/by/4.0/ (c) (i) Open Access

\begin{abstract}
Music narration absorbs the theory of literature narration and studies the narration in music by combining the music text with the unique sound vocabulary of music. Text and music sound are the organizational forms of music narration. Music text mainly refers to the title, lyrics, opera script or a small amount of narration of music works, which are presented in the form of words; music sound mainly refers to the organization of music sound system according to certain music logic, which is presented in the form of sound. This study first combs the development process, methods and main points of literary narrative theory, combines its theory with music narrative, focuses on the analysis of the organizational form of music narrative, and expounds the practical application of music narrative in music creation and music analysis combined with music works, so as to have some enlightenment for understanding music and its cultural connotation.
\end{abstract}

\section{Keywords}

Narrative, Text, Music, Vocabulary

\section{Narrative Theory}

In the 1960s, many French literary theorists, semioticians and folk literature experts created and developed a common theoretical proposition about narratology. At the beginning of the emergence of narrative theory, they focused on the internal structure of narrative works. In the 1980s, narrative theory incorporated social, historical and psychological factors that had been excluded from the scope of narrative research into narratology. It is a multi-dimensional narrative research paradigm. Music narrative analysis absorbs literary narrative theory, combines music text and music specific sound vocabulary to study music narra- 
tive.

Narrative theory can be traced back to Aristotle's Poetics In poetry (1996), the media, objects and methods of poetry imitation, tragedies plot, character, language, thought, scene and aria, poetry, comedy, epic, rules of tragedy creation and so on, though short in length, are the essence of the theory, and they are inspiring to the generation of later narrative theory. Narrative theory is one of many literary theories, which occupies an important position in literary theory. It has gradually expanded from literature to painting, music, dance, film, television and many other art fields, and has been widely spread in academic and literary circles. The translation and introduction of narrative theory in Chinese academic circles can be seen in the study of narratology edited by Zhang Yinde (1989). In the preface, the editor introduces in detail the history of the emergence and development of narratology and the literary theories of the representative scholars of early French narrative theory in the 1960s-1980s. Later, most of the works on narrative theory are quoted from this translation.

The core of narrative theory is the text itself, which is influenced by structuralism and Russian formalism. The linguistic system established by the Swiss linguist Ferdinand de Saussure is considered to be the creation of structuralism. Saussure believes that "the study of language should be based on the relationship between the components of a certain language phenomenon, from the internal structure of language, rather than from its historical evolution." "Structuralism, as a methodology, emphasizes that in the study of things, we should not pay attention to causality, but should examine and grasp things from the whole of things and from the correlation of the internal elements that constitute the whole of things." After analyzing one hundred Russian folktales, V. Propp, the representative of Russian formalism and the expert of Russian folktales, published the book morphology of Folktales (1928). The book points out that: "according to the surface phenomenon, these 100 stories are complicated, strange and changeable, but they are essentially restricted by a constant and difficult structure. This structure is embodied in the 31 'functions' which are connected in strict and unchangeable order." The French anthropologist Cl. Lévi Strauss wrote structure and form (1960), which introduced the function and structure of pop folktales to the French academic circles. There were a lot of attempts to analyze the structure of narrative works (Zhang, 1989: pp. 2-3). Under the influence of structuralism in the field of French literature research and the direct inspiration of Russian formalism, narrative theory was formally established in France.

The Narratology before the end of 1980s is called "classic narratology" in the academic circle, which is characterized by "relying on structuralism to carry out text analysis, focusing on exploring the internal structural rules of narrative works and the relationship between various elements"; the Narratology since the 1990 s is called "post classic narratology". It is characterized by "breaking the barriers of pure text analysis and combining text analysis with other research 
methods" (Jiang, 2018: p. 3), Such as feminism, bakhtinism, structuralism, reader response criticism, psychoanalysis, historicism, rhetoric, film theory, discourse analysis and (spiritual) language communicate with each other, so as to form a situation in which the research of narrative theory is integrated and developed in depth, which leads to various deformations in the research of narratology (Tan, 2014: p. 186). In 2009, German scholar Ansgar Nünning proposed 16 kinds of contextualistnarrarologies:

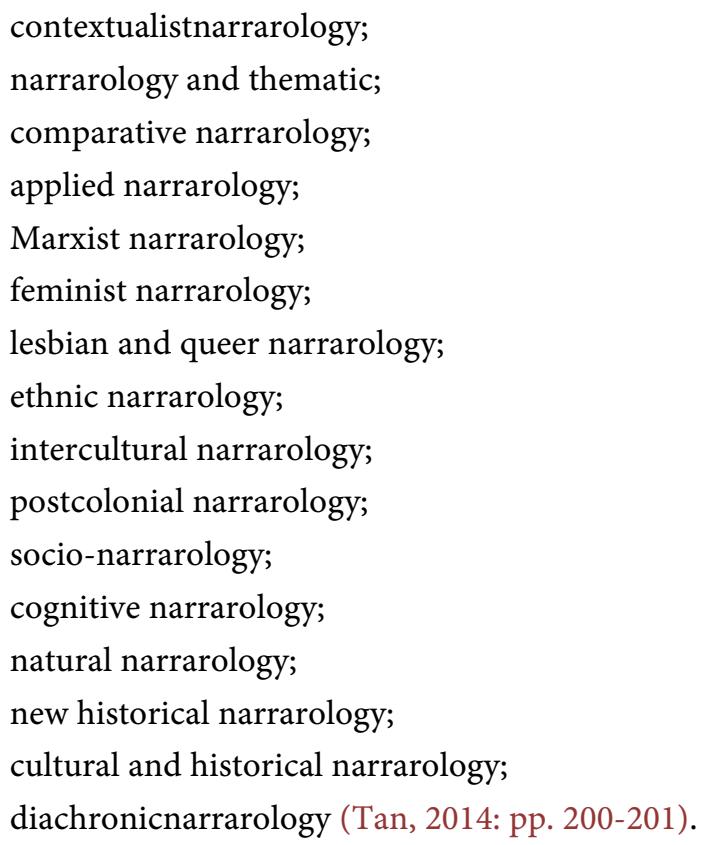

The above-mentioned narrative themes of different orientations inject new perspectives and ways of thinking into narrative theory. In the process of the development of the post classical narrative theory, a recognized view is that the reconstruction of the classical narratology can't be completely separated from the traditional narrative theory system, and the text ontology issues concerned by the traditional narratology can't be separated from the social and cultural context. Therefore, the new development of narrative theory should be a multidimensional paradigm, in which the deeper connotation and characteristics of narrative object can be found.

\section{The Organizational Form of Music Narration}

Music narrative is deeply influenced by literary narratology. It absorbs classical narrative and post classical narrative theory to interpret, comment or criticize music works and interpret their cultural significance. American scholar Edward T. Cohen (2011) proposed "If music is a language, then who is speaking" in his book the voice of the composer's personality. "My task is to think about what the idea of 'music is a form of speech' means, rather than to determine what such speech specifically wants to say". The author thinks that music has a certain context, which contains humanistic content. The context of music and humanis- 
tic context are always closely related, and the context needs to meet the music performance potential. The author carefully analyzes the narrative in music, which can be verbal or non-verbal.

In the development of music narrative theory, there is a controversial issue, that is, whether music is narrative, especially pure music. Jean-Jacques Nattiez of the University of Montreal in Canada believes that it does not exist strictly in the fictional sense, strictly speaking, narration does not exist in music, it exists in the imaginary or fictional plots inspired by specific objects ... For the audience, any 'narrative' instrumental music has no narrative in itself, which exists in the structural analysis of non-narrative music (Wang, 2013: p. 7). Carolyn Abbate, a musicologistsaid: "If our little structuralist analysis has implied that, as an extreme example, a formalist or absolutist can analyze all music as narration, then we can still regard music as an art form without specific content (not to mention cultural or cultural or ideological implication). This means that it is ineffective to call for literary and theoretical analogy. But if we use narrative metaphor to express music (regard the tone change as 'departure' and harmony as 'continuity of action'), or grasp the 'Cape' of literary criticism to present new categories and terms, what can such music narrative theory tell us? Perhaps there is a situation that suggests to Nattiez that is, music analysis itself originates from the impulse of narration, and we create imagination about music, so as to show that no other form of interpretation can be competent for music interpretation. Perhaps the concept of narration is so important to the rational formation of human experience that we can't help but explore the analogy between narration and music, regardless of what kind of arbitrariness and futility this may lead to" (Wang, 2013: p. 9). Although Nattiez, Abbate and other scholars hold a skeptical or even negative attitude towards music narrative, they still think that music has the characteristics of "repetition", "expectation" and "solution" similar to literature narrative. These characteristics are either explicit or implicit, which makes the application of narratology in music analysis possible. They emphasize that music narrative analysis cannot copy literature narrative theory framework.

Music narration has something in common with literature narration, such as the narrative technique of opera script and drama script, the narrative method of song and narrative poem, but it is different from the vocabulary or grammar used in literature narration. For pure music, the narrative medium of sound is completely different from that of literature narration of words (Language). Music narration has its own narrative characteristics, Such as the logical structure of theme, response, presentation, discussion and summary in fugue works; the three part structure principle and the comparison principle of the main theme and the sub theme of the classical sonata are as follows: the presentation part (the main theme, the connection part, the sub theme and the ending part), the development part (the development of the theme material in the presentation part, the introduction of new materials or the free and changeable), the reproduction part (the main theme, the sub theme and the ending part). 
Music narrative has its own narrative language and narrative mode. Some scholars summarize the theory of music narrative as follows: "the ability of music to express a complete and specific story may be limited, but music has obvious or implicit narrative characteristics, and it is good at expressing various emotional states. Composers, listeners and researchers can connect different emotional states with their own experience to imaginary constitutes a series of narrative plots with certain order, law and logical relationship, so music has narrative function. The research boundary of music narrative theory can't be limited to music works with titles or text descriptions, and all forms and styles of music works can be included in the research scope of music narrative theory" (Wang, 2013: pp. 12-13). Generally speaking, music narrative has four-dimensional structure mode: composer, music works, music performer and receiver (some music works integrate three-dimensional or four-dimensional structure mode). In this four-dimensional structure mode, the study of music narrative should not only pay attention to the internal narrative structure of music works, but also its horizon should be related to the composer's concept, attitude, position, mood, performer's knowledge, music technology level, understanding of music works, and receiver's listening experience, knowledge reserve, social life experience, aesthetic values, ideology and psychological state. They make music narration possible.

\section{The Practical Enlightenment of Music Narration}

For composers, before composing, they should first conceive the theme image or story plot of the music they narrate, that is, the "bamboo in the heart" in the creation of ancient Chinese literature and art works. After they conceive the things they narrate, they should choose the appropriate musical vocabulary to create. Generally speaking, the major expresses the story scenes and emotions that are clear, firm, and righteous, while the minor shows the story scenes and emotions of dim, worrying, and hesitant.

For example, Chopin's Etudes in C minor (also known as the "revolution" etudes) used minor to express the inner feelings of sadness and indignation after the failure of Warsaw revolution in 1831. At the beginning of this piano piece, the right hand used the second transposition of the D ninth chord to express the feelings of sadness and indignation with great strength, and the left hand used the sixteenth note to tilt down rapidly and sharply to show the anger of Warsaw people in the war. The resolute melody of the high part of the work is just like a horn. This work narrates a complete story scene through the unique harmony color and music vocabulary.

Another example is the Violin Concerto "Liang Zhu" composed by He Zhanhao and Chen Gang in 1958, which tells the story of Liang Shanbo and Zhu Yingtai. It is a well-known love story. Based on the melody of Yueju Opera, the work adopts the techniques of symphony and Chinese folk opera music, carefully designs the layout according to the plot development, adopts Sonata structure, 
single movement and subtitle. The main contents are grassbridgesworn, Yingtai anti-marriage, and butterflies in front of the grave. In the music of the presentation section, the introduction mimics the sound of a bird with a flute, and then the oboe displays a beautiful scene with beautiful spring and the fragrance of birds. The main part first plays the poetic love theme by the violin. Next, cello answers with the light and soft tone of violin. Finally, all the bands play the theme of love again, which shows the sincere and pure friendship between Liang and Zhu and their deep love for each other. The music of the connection part is a melody in sharp contrast to the theme of love. It is developed from the theme phrase, and the rhythm of this passage is free and colorful. The theme rhythm of the sub part is clear and cheerful, and many places use the way of jumping to make the melody lively and jumping. The solo and band appear alternately, which vividly shows the happy life of the students of Liang and Zhu for three years. At the end, the music turns to adagio, and the passionate dialogue between Violin and Cello appears again, playing in the form of polyphony, in which the intermittent tone shows Yingtai's inner feelings of hesitation, contradiction and shyness. It shows the scene of seeing each other off in the 18 phases sending, saying goodbye in the long Pavilion and reluctant to part. The music in the develop part describes the plot of anti-marriage, building meeting, crying, accusing and throwing graves. In the anti-marriage plot, the brass pipe plays the theme of ferocity and cruelty of feudal forces with stern rhythm and gloomy tone; the solo violin uses the rhythm of scatterboard to state the sadness and panic of Yingtai, and the band's strong allegro sets off the theme of the solo violin's resolute opposition to feudal forces. These two themes gradually intensified, forming the scene of Yingtai's resentment against marriage. Although the band played in full, giving people a yearning for a happy life, but the feudal forces represented by the brass gave great pressure. The plot of the stage meeting is also a adagio, the dialogue between the big Violin and the violin, the lingering, sad, weeping tone, which vividly shows the mixed feelings of Liang and Zhu when they meet on the stage. The plots of mourning, accusing and throwing graves alternate between the solo of Violin and the allegro of the orchestra. The changes use the techniques of Beijing opera's leading board and Yue Opera's slow singing, which deeply shows the bloody and tearful accusing of feudal ethics in front of the graves. Finally, gongs and cymbals sing together, and the music reaches its climax. The music of the reproduction part mainly describes the scene of the butterfly. The flute plays out the soft and beautiful colorful melody, and set off each other with the playing of harp, leading people to a mythical fairyland. The solo violin once again plays the theme of love, showing that Liang Shanbo and Zhu Yingtai, after they died under the oppression of feudal forces, turned into a pair of butterflies and danced happily and freely in the flowers.

The above two works belong to the title music and have no lyrics. The narrative quality of these pure music works is no less than that of those with lyrics or literary works. It can be seen that the sound form of music itself has narrative 
function, and there is no music works without narrative, but some music works are explicit narrative, and some music works are implicit narrative. These explicit or implicit narratives require music performers and music receivers (listeners, viewers) to perceive and comprehend from the sound symbols of music. Different musical instruments, human voice, harmony progression, rhythm and speed, mode and tonality show different musical images. Therefore, music can narrate all the cultural events of human society, can depict the profound cultural connotation, its narrative is beyond doubt.

\section{Conclusion}

Music has the basic narrative theory elements and structural form advocated by scholars. Music narrative is also a music analysis method in addition to the analysis of music rhythm, melody, harmony, form, mode, tonality, theme, image, style and sound. Before narratology officially appeared as a subject name, there was no lack of narrative analysis of the text, discourse, characters, plot, environment and other elements of musical works in music analysis. Even if it is pure music, people interpret the narrative nature of abstract music with the help of distinct contrast theme, rich sound expression, technical means of music development or titles with symbolic narration. Compared with pure music, title music has a clear narrative direction, from abstract to concrete, the lyrics of songs and operas present complete narrative content, and its narrative function is consistent with literary narrative. Therefore, music narrative can express a relatively complete plot and show the social and cultural form behind the story, and its text or sound vocabulary is the basis of narrative.

\section{Fund Project}

Sichuan University of Arts and Sciences 2017-2019 school level education and teaching research and reform general project (subject number: 2017JY37); Scientific research project of Sichuan University of Arts and Sciences (subject No.: 2019PT002Y); Ministry of Education Industry University cooperation collaborative education project "New continent Technology Group Co., Ltd." funding (subject No., 201902295014).

\section{Conflicts of Interest}

The author declares no conflicts of interest regarding the publication of this paper.

\section{References}

Aristotle. (1996). Poetics. Beijing: Commercial Press.

Edward, T. C. (2011). Composer's Personality Voice (X. He, Trans.). Shanghai: East China Normal University Press.

Jiang, S. (2018). Narrative Form and Subject Evaluation (Revised Version). Wuhu: Anhui Normal University Press. 
Tan, J. (2014). Introduction to Narratology: From Classical Narratology to Post Classical Narratology (2nd Edition, pp. 186, 200-201). Beijing: Higher Education Press.

Wang, X. (2013). Art of Speech: Introduction to Music Narrative Theory (pp. 7, 9, 12-13). Beijing: People's Music Publishing House.

Zhang, Y. (1989). Research on Narratology (pp. 2-3). Beijing: China Social Science Press. 